\title{
Ser-cuidador de familiar com câncer e dependente: um olhar para a temporalidade*
}

\section{To be the caregiver of a family member with cancer and dependent: a glance to temporality}

\author{
Joisy Aparecida Marchi ${ }^{1}$, Ligia Carreira ${ }^{2}$, Catarina Aparecida Sales ${ }^{3}$
}

\footnotetext{
* Artigo original extraído da dissertação de Mestrado "Vivências dos cuidadores de familiares de pessoas com câncer e dependentes: uma análise existencial”, apresentado ao Programa de Pós-Graduação em Enfermagem da Universidade Estadual de Maringá (UEM), em 2013.

${ }^{1}$ Enfermeira, Mestre em Enfermagem. Enfermeira da Prefeitura Municipal de Astorga. Astorga, PR, Brasil. E-mail: joisymarchi@hotmail.com.

${ }^{2}$ Enfermeira, Doutora em Enfermagem. Professora Adjunto da UEM. Maringá, PR, Brasil. E-mail: ligiacarreira.uem@gmail.com.

${ }^{3}$ Enfermeira, Doutora em Enfermagem na Saúde do Adulto. Professora Adjunto da UEM. Maringá, PR, Brasil. E-mail: casales@uem.br.
}

\section{RESUMO}

Objetivou-se compreender a significação, para o ser-cuidador, da responsabilidade de assistir um familiar com câncer e dependente. Estudo fenomenológico heideggeriano realizado junto a 17 cuidadores familiares por meio de entrevistas. Foram respeitados os preceitos éticos. Da análise emergiu a seguinte temática: "Desvelando a temporalidade de conviver com o câncer no lar". O cuidador, ora rememorou o seu vigor de ter sido e, se manteve preso a essa ek-stase, ora vislumbrou um porvir promissor e modificou o seu instante. Os profissionais que acompanham as famílias ao enaltecer o porvir podem tornar o instante realista e menos sofrido para o cuidador. Olhar para a temporalidade faz-se necessário para que se alcance o objetivo maior dos cuidados paliativos e da enfermagem, ou seja, assumir o seu projeto essencial de ser um ser-do-cuidado.

Descritores: Cuidadores; Atenção Primária à Saúde; Enfermagem Oncológica.

\section{ABSTRACT}

We aimed to comprehend the meaning of being a caregiver, the responsibility to assist a dependent family member with cancer. A phenomenological heideggerian study conducted with 17 family caregivers through interviews. Ethical precepts were respected. The following theme emerged from the analysis: "Unveiling the temporality to live with cancer at home". The caregiver recalled his strength of being and maintaining himself stuck to this ecstasy and sometimes glimpsed a promising future and changed his reality. Professionals guiding families can turn the moment of realization less painful for the caregiver. It is needed to glimpse the temporality to reach the major goal of palliative care and nursing, that is, to assume the essential project to be a caregiver.

Descriptors: Caregivers; Primary Health Care; Oncology Nursing. 


\section{INTRODUÇÃO}

Nas últimas décadas, familiares têm procurado assistir a demanda emergente de pacientes portadores de doenças crônicas, incapacitantes e/ou terminais. Quando um integrante da família adoece, é no seio familiar que se reúne a fonte de cuidados e a atenção necessária para minimizar as dificuldades decorrentes do adoecimento ${ }^{(1)}$.

Como o período de internação hospitalar, comumente, é reduzido e o paciente com câncer é acompanhado via ambulatório, cuidadores familiares assumem a responsabilidade do cuidado físico e emocional do doente no domicílio. Soma-se a isso o auxílio nas atividades da vida diária, transporte, cuidados específicos com a doença, na comunicação com os

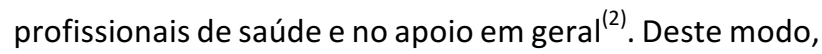
os cuidadores podem enfrentar uma série de estressores em virtude das mudanças ocorridas, levando a piora nas condições de saúde, financeira, social e ocupacional ${ }^{(3)}$ com consequente redução do seu bem-estar global ${ }^{(4)}$.

À medida que a doença progride e a morte se aproxima, o familiar torna-se cada vez mais dependente de auxilio $^{(4)}$. Isso pode sobrecarregar o cuidador, objetivamente, no tocante as tarefas relacionadas aos cuidados e o tempo envolvido em sua prestação, bem como no âmbito subjetivo, que condiz com a sua experiência e aos sentimentos sobre essa função(5). Assim, o cuidador precisa repensar o seu papel ao longo da temporalidade, com a necessidade de ressignificação da própria vida ${ }^{(6)}$.

Neste cenário, é fundamental que o cuidador seja informado sobre a provisão de cuidados no domicílio, pois o despreparo para assistir o seu familiar é tido como um complicador no atendimento das demandas emergidas ${ }^{(7)}$. O processo de orientação contínua ofertado pela equipe de cuidados paliativos é imprescindível, por oferecer um sistema de apoio aos pacientes e familiares ${ }^{(7)}$.

A prática adequada dos cuidados paliativos preconiza olhar o ser humano na sua totalidade, independente do ambiente em que esteja inserido, podendo garantir uma assistência humanizada e de qualidade ${ }^{(8)}$. Nessa perspectiva, os cuidados paliativos não devem ser uma alternativa à ineficácia dos tratamentos, mas uma filosofia de cuidados que deve perpassar todas as fases da doença $^{(9)}$.

Neste pensar, apesar da Atenção Primária à Saúde, representada pela Estratégia Saúde da Família (ESF), não ser originalmente responsável e atuante na assistência paliativa, esta pode contribuir no atendimento das famílias que convivem com o câncer, já que possuem o vínculo, a corresponsabilização e o atendimento de maneira integral e contínua como eixo norteador de suas ações ${ }^{(10)}$. Nesses momentos a família pode vivenciar a dor total, ou seja, além da dor física, tem que enfrentar outras tão angustiantes e agudas quanto esta, as quais a afetam psicológica, existencial e espiritualmente, fazendo-as simplesmente quedar-se ante sua situação ${ }^{(11)}$.

Considerando que é no seio familiar em que cada vez mais o câncer será experienciado e, que há a necessidade de responsabilização da família pela pessoa no próprio domicílio, suscitando diferentes sentimentos na temporalidade desse novo papel, o foco desta pesquisa buscou refletir: como o cuidador de familiar com câncer e dependente tem vivenciado, ao longo do tempo, o cuidado do outro? Ante o exposto, esta pesquisa teve por objetivo compreender a significação, para o ser-cuidador, da responsabilidade de assistir um familiar com câncer e dependente.

Pesquisas com este escopo justificam-se visto que há significativas mudanças na vida do cuidador decorrentes dessa nova função. Além disso, a necessidade de ressignificação, em virtude da vivência temporal, deve partir do próprio cuidador, mas, deverá contar com o apoio das equipes de saúde, não permitindo que se mantenha a condição de cuidador inseguro, solitário e adoecido pelo cansaço ${ }^{(6)}$. Ademais, compreender as vivências de ser cuidador de um familiar com câncer fora de possibilidade de cura, pode contribuir para efetiva assistência de enfermagem com um planejamento assistencial coerente e resolutivo ${ }^{(12)}$. 


\section{MÉTODOS}

Pesquisa qualitativa de abordagem fenomenológica consolidada nos pressupostos heideggerianos ${ }^{(13)}$. Os depoentes foram os cuidadores familiares principais de pacientes com câncer com Escala de Performance Paliativa (PPS) menor ou igual a 40\%; que estavam cuidando de seu familiar há, no mínimo, três meses; tinham idade superior a 18 anos e condições físicas e preservação do estado cognitivo para responder as perguntas, sendo esses os critérios de inclusão do estudo. A PPS, escala que avalia cinco dimensões funcionais ${ }^{(14)}$, foi utilizada com a finalidade de identificar os pacientes com alta dependência para as atividades da vida diária.

Os participantes foram selecionados a partir da ESF de um município do Noroeste do Paraná, escolhidos entre as equipes vinculadas aos Núcleos Integrados de Saúde (NIS) com maior número de equipes de ESF cadastradas no Cadastro Nacional de Estabelecimentos de Saúde (CNES).

Após contato com as equipes, a pesquisadora foi apresentada aos cuidadores pelos enfermeiros e/ou Agente Comunitário de Saúde, que a levaram até os domicílios das famílias. Nos casos em que os critérios de inclusão para pesquisa eram obedecidos, a pesquisadora realizava o convite para uma próxima visita e participação no estudo. Para coleta dos dados foram realizados três encontros com os participantes com o intuito de que uma empatia fosse criada e que se sentissem seguros em falar de suas vivências

No inicio da coleta os participantes receberam orientação quanto aos objetivos do estudo, assim como os seus direitos, sendo solicitado nesse momento a assinatura do termo de consentimento livre e esclarecido. $\mathrm{Na}$ condução da entrevista foi apresentada a seguinte questão norteadora: “Como está sendo para você cuidar do (nome do familiar com câncer)?". A entrevista fenomenológica ocorreu em encontro individual, singularmente instituído entre a pesquisadora e o cuidador, possibilitando um movimento de compreensão do vivido do ser humano, tal como se apresenta na sua vivência cotidiana. Para tanto foram necessárias a ambientação, a empatia e a intersubjetividade, possibilitada pela redução de pré-conceitos ${ }^{(15)}$.

As entrevistas tiveram duração média de 40 minutos, sendo utilizado um gravador como recurso eletrônico para captar integralmente as falas. Ao desenvolver a etapa de trabalho de campo concomitante com a da análise, determinou-se o número de depoentes, 17, uma vez que mostrou a suficiência de significados capaz de responder aos objetivos da pesquisa ${ }^{(16)}$. Com o intuito de preservar o anonimato dos participantes, estes foram apresentados por pseudônimos de anjos.

Para captar a plenitude expressa pelos sujeitos em suas linguagens, optou-se pela análise individual de cada discurso. Assim, a priori, realizaram-se leituras atentas de cada depoimento, separando os trechos ou unidades de sentidos (us) que se mostraram como estruturas fundamentais da existência dos participantes entrevistados $^{(17)}$. A posteriori, passou-se a analisar as unidades de sentido de cada depoimento, realizando seleção fenomenológica da linguagem de cada sujeito ${ }^{(17)}$, que deu origem às temáticas ontológicas, analisadas à luz de algumas ideias heideggerianas, como também de estudiosos sobre o tema e, pesquisadores que versam sobre os cuidados paliativos.

A etapa de campo ocorreu entre os meses de novembro de 2012 e fevereiro de 2013, sendo respeitadas as normas brasileiras para a realização de pesquisas com seres humanos. $O$ projeto que deu origem a pesquisa foi aprovado pelo Comitê Permanente de Ética em Pesquisa com Seres Humanos da Universidade Estadual de Maringá, processo no 435/2011.

\section{RESULTADOS}

Fizeram parte do estudo 17 pessoas, 16 do sexo feminino, a maioria casados/amasiados, somente uma solteira e outra separada. Sobre a profissão atual, a maior parte dos cuidadores era do lar e aposentados, uma massoterapeuta, uma administradora, uma auxiliar de enfermagem e os outros se afastaram do trabalho em virtude da nova ocupação. A seguir, o Quadro $1 \mathrm{com}$ as principais características dos depoentes. 
Quadro 1: Principais características dos cuidadores entrevistados. Maringá, PR, Brasil, 2013.

\begin{tabular}{|c|c|c|c|c|}
\hline Depoentes & Idade & Parentesco & Tempo Diagnóstico/ Localização Inicial & PPS (\%) \\
\hline Zadkiel & 70 & Esposa & 2 anos/ Orofaringe & 40 \\
\hline Ariel & 67 & Esposa & 8 meses/ Intestino & 30 \\
\hline Jeremiel & 56 & Esposa & 2 anos/ Próstata & 40 \\
\hline Miguel & 51 & Tia & 1 ano / Mama & 40 \\
\hline Morael & 46 & Filha & 4 meses / Estômago & 10 \\
\hline Shateiel & 43 & Prima & 3 meses / Encefálico & 20 \\
\hline Rafael & 59 & Mãe & 6 meses / Estômago & 30 \\
\hline Fanuel & 44 & Esposo & 1 ano / Intestino & 20 \\
\hline Jofiel & 69 & Esposa & 3 meses / Orofaringe & 40 \\
\hline Afriel & 70 & Esposa & 6 meses / Intestino & 30 \\
\hline Manu & 60 & Filha & 5 meses / Estômago & 20 \\
\hline Gabriel & 49 & Esposa & 2 anos / Pulmão & 30 \\
\hline Antriel & 50 & Filha & 7 meses / Estômago & 40 \\
\hline Uzziel & 70 & Esposa & 4 meses / Bexiga & 30 \\
\hline Caliel & 55 & Filha & 1 ano / Útero & 20 \\
\hline Haniel & 42 & Filha & 4 meses / Intestino & 30 \\
\hline Camael & 55 & Esposa & & 40 \\
\hline
\end{tabular}

A partir da análise da linguagem dos participantes, emergiu a seguinte temática ontológica apresentada a seguir.

\section{Desvelando a temporalidade de conviver com o câncer} no lar

Nesta temática são apresentadas as vivências dos cuidadores de doentes com câncer e dependentes enquanto seres temporais e históricos, demonstrando que a temporalidade é afetada tanto na vida do doente, quanto no seio familiar como um todo.

\section{Relembrando o vigor de ter sido do doente}

[...] ver o sofrimento dela, querer comer e não poder, tomar alguma coisa e dali a pouco jogar tudo fora, antes ela comia com tanto gosto! Dava gosto de ver ela comer e agora não dá mais, eu me sinto triste em ver ela assim, tem dias que eu não consigo dormir (Fanuel).

A gente fica agoniada, ver um homem tão forte, trabalhador em cima de uma cama a gente sofre, é muito duro, não é fácil não. Ele saía, trabalhava bastante $e$ voltava para casa, a gente morou uns anos fora também, lá em Rondônia, ele era tão forte [...] (Camael).

\section{Recordando seu próprio vigor de ter sido}

Eu acho que eu me acabei muito, faz muito tempo que eu não vou a lugar nenhum, antigamente eu fazia caminhada, fazia artesanato, fazia de tudo, mas agora não faço mais nada, não dá tempo, teve um tempo que eu voltei a fazer, mas ficava preocupada com ele e quando eu voltava ele estava reclamando daí eu parei, as horas que eu tenho livre eu durmo ou faço crochê (Jofiel).

A gente parou no tempo, eu não vou mais no centro para comprar uma roupa, saía daqui ia para o centro de sábado com as meninas e eu não vou mais em lugar nenhum, parei, parei [suspira]. Então é casa, casa, médico, casa, é triste né, ai não dá, eu queria sair disso (Zadkiel).

[...] eu vivia na praia com a minha filha passeando, ficava quinze dias ou 20 dias, ela tinha piscina eu vivia na piscina, ia a aniversários, festas de casamento, eu passeava muito, ia para o centro, ia à igreja a pé e voltava, eu cheguei há ficar três anos sem ir para o centro, minha vida mudou, eu me dedico aqui, eu passo dois, três dias sem sair do portão, então minha vida mudou, mudou muito, mas eu me sinto feliz porque eu cuido dele de corpo $e$ alma, às vezes eu fico triste, mas não choro (Uzziel). 


\section{Vislumbrando no porvir respostas aos seus anseios}

[...] é difícil a gente está junto em uma caminhada e de repente acontece uma coisa dessas a gente torce muito para que ele fique logo curado, como eu torço, todo dia e peço a Deus porque é meu companheiro, tanta coisa juntos, quando eu não toco no assunto eu fico melhor, mas quando a gente tem que falar sobre isto eu me emociono muito, peço até desculpa para você [choro] (Gabriel).

[...] eu era uma pessoa que vivia com muito medo do amanhã, e chegou um ponto que eu tive que esquecer esse medo e lutar pelo dia de hoje, só quem passa por isso sabe [...] a gente tem fé que ele vai ser curado, crê que Deus faz a obra completa [para, olha para o nada] o sofrimento faz você aprender muita coisa, aprende a ter paciência e principalmente saber esperar (Rafael).

\section{A temporalidade concedendo a compreensão da situação} Uma coisa que eu aprendi foi buscar mais Deus, confiar nele, aprendi também a olhar mais para a gente, ter mais amor. Pode acontecer comigo também então eu tenho que me cuidar um pouco mais. Parei de fumar. Hoje faz três meses, ainda que demorei, tentava e não conseguia. Muitos lutando para ficar bem de saúde e a gente jogando a vida fora?! (Antriel).

Esses dias eu estava pensando que isso é um aprendizado na vida da gente, eu era tão limpinha com a casa, me achava né, tudo fedia para mim! Pensava que não ia passar por isso nunca, eu era muito orgulhosa, então fui pensando que a gente não é nada, todo mundo precisa de ajuda, um dia pode ser eu e daí? Orgulho não leva nada a ninguém, a gente tem que estar sempre disponível para ajudar [...] isso fez muitas coisas mudar, comecei a agir e pensar de forma diferente, pensar que não dá para deixar para depois tem que pegar e fazer, tudo mudou na minha vida, aprendi a fazer as coisas de coração e fiquei feliz ao ver que eu pude me tornar outra pessoa (Haniel).

[...] vi muitas pessoas internadas, cada um com uma doença diferente, e isso é muito triste de ver [choro], gente morrendo do lado dela, acho que isso faz a gente pensar muito [para, reflete e diz:] passei a dar valor nos mínimos detalhes da vida, dinheiro nenhum paga sua saúde! (Shateiel).

\section{DISCUSSÃO}

$\mathrm{Na}$ analítica heideggeriana o ser, também denominado por ele de Dasein, ser-aí ou ser-no-mundo, é a maneira como algo se torna presente, manifesto, percebido, compreendido e, finalmente, conhecido para o ser humano ${ }^{(18)}$. Sua existencialidade é inseparável da temporalidade, o homem só existe porque está fundamentalmente ligado ao tempo, além disso, discute não apenas em uma soma de momentos, mas uma compreensão, no sentido mais profundo, do futuro, do passado e do presente ${ }^{(13)}$.

O ser humano é o único ente capaz de unir conscientemente o que já foi e o que é ou será, ou seja, de recomeçar ou reconstruir sua vida. Existir é o mesmo que temporalizar-se. A temporalidade ilumina, pois é, o aí do ser, a presença em sua existência (19). "É o ser que assume propriamente a sua existência, levando-a a um grau de responsabilidade por todos os modos de realização de sua presença na temporalidade"(18). Os alicerces naturais da existencialidade do ser-aí são a temporalidade e a historicidade ${ }^{(13)}$.

A temporalidade não se identifica com as coisas, antes possibilita a manifestação de homem e mundo, uma vez que, o sentido do ser se revela por meio da temporalização ou da abertura do tempo denominada temporalidade $^{(13)}$. Na decisão antecipativa, ou seja, na forma originária e autêntica do cuidar, o ser-no-mundo desvela todo o seu poder-ser, que se manifesta em uma constituição temporal $^{(20)}$.

Nesta temporalidade, o ser-aí se torna também histórico, mas a historicidade deste ser não reside no simples fato dele ser objeto ou sujeito da história, mas de ter um destino. E o que de fato faz parte da existência humana só se pode conhecer na história, no modo de ser em que predomina seu percurso temporal no mundo ${ }^{(18)}$. E neste caminhar existencial é possível temporalizar-se 
conforme três ek-stases, o porvir (futuro), o vigor de ter sido (passado) e a atualidade (presente). O futuro referese às possibilidades de ser, o passado ao retorno ao vivido e o presente à ocupação ${ }^{(13)}$. Essas ek-stases são "mobilizações" que empurram a presença e não se sucedem uma à outra. O futuro não vem depois do passado e o passado não vem antes do presente. A cada instante, a presença é o seu porvir, o seu ter-sido e o seu presente $^{(19)}$.

Concebeu-se nas linguagens dos depoentes que conviver com o câncer nesse ek-stante fez com que os cuidadores projetassem e relembrassem o quão saudável era o seu familiar em seu vigor de ter sido. "O passado sempre tem sentido somente, na medida em que é visto a partir de um presente" ${ }^{(21)}$. Notou-se, ainda, que, nesta atualidade, os cuidadores também expressam pesar ao rememorar que em seu vigor de ter sido traziam a vida dentro de si que foi retalhada pela doença de seu familiar. Neste ek-stante, convivem com o vazio de suas almas.

A necessidade de cuidar de um membro da família dependente expõe o cuidador a uma série de circunstâncias adversas e provoca mudanças em seu estilo de vida. Essas alterações afetam seus sentimentos, seu dia a dia e sua vida em geral $^{(22)}$. O cuidador passa a realizar atividades relativas ao atendimento de necessidades básicas, gerando uma atenção permanente e desgastante ${ }^{(23)}$.

Assim, ao conviver com o câncer no lar, o familiar cuidador pode retomar o seu passado e descortinar sua trajetória de dor e sofrimento, bem como sentir que as emoções do seu vigor ainda permanecem vivas em seu presente ${ }^{(11)}$. "O ser humano pode voltar ao passado, porque a vida se compacta, se cristaliza sob formas significativas, de sentido e valor" ${ }^{\prime 21)}$. Dessa forma, sua historicidade mostra as lembranças do vigor de ter sido do ser-cuidador e de seu familiar adoecido, desvelando na história não somente o que passou, mas também a sua origem e seu significado para a pessoa, considerando o vivido do ser em sua cotidianidade.
Sendo este ser um ser temporal, esta temporalidade de existir-no-mundo cuidando de um familiar com câncer o faz compreender-se sempre dessa ou daquela maneira, haja vista que o estar-fora-de-si também traz consigo a possibilidade positiva de tornar-se um todo em alguma coisa. Vislumbrou-se em algumas falas que o tempo de cuidar é o mesmo tempo de sentirem-se-fora-de-si ao conviverem com sentimentos de medo e tristeza perante a agressividade da doença. Nesses momentos, o tempo que trouxe tantas verdades tristonhas e mentiras risonhas surge como um raio de esperança num porvir prazeroso.

O porvir tem primazia sobre as demais ek-stases, uma vez que é nele que o ser-aí tem a possibilidade de antecipar-se e propriamente vir a si. Todavia, não se trata de apreender o futuro como extensão do passado e do presente, mas como porvir, um porvir a partir do qual emerge a possibilidade de uma passagem, que reponha o humano numa relação originária com o ser. Um poderser, um salto, um salto de liberdade que, abismando-se no nada, funda outro modo de ser para o humano, que se chama presença por possibilitar ao humano ser o "aí" do $\operatorname{ser}^{(19)}$.

O futuro abre o poder-ser do Dasein o que é condição crucial para a autocompreensão projetiva ${ }^{(20)}$. Portanto, todo poder-ser tem condições de vir a si, porque o seu ser já está lançado numa realidade, para tanto se faz necessário refletir sobre a sua condição enquanto ser-nomundo, assumindo ou recusando as diferentes possibilidades $^{(20)}$. Assim, alguns depoentes encontram motivos para manter um porvir esperançoso e, apesar de todas as dificuldades impostas pela elevada dependência, seguem fortes na batalha contra a doença.

A compreensão do existir humano não é algo que acontece de imediato, vai-se constituindo no tempo pelas articulações dos significados que o ser-no-mundo expressa ao mundo, pois enquanto um ser-aí, o homem atribui sentido às coisas com as quais se relaciona no horizonte de sua existência. O ser humano vive seu cotidiano a cada momento, e nesse viver existencial 
vivencia sentimentos de tristeza e alegria, aos quais expõe os outros ao seu redor, por meio de sua linguagem ${ }^{(13)}$.

Logo, alguns participantes encontram-se presos ao momento presente e ao vigor de terem sido, não vislumbrando um porvir antecipativo e nem as suas diferentes possibilidades. Averiguou-se que, por vezes, ocultam a facticidade da doença em seu seio familiar e sentem-se aflitos com as alterações em sua temporalidade. Em relação à vivência como ser-cuidador não conseguem visualizar algo de positivo e/ou reconstrutor para sua vida.

Mas, também se interpretou nos depoimentos que ver o sofrimento do outro, os fez emergir de seu cotidiano e buscar forças para enfrentar os seus próprios temores, deixando vir a si o seu poder-ser mais próprio. Em suma, ainda que a vivência da doença não foi a sua, por compartilhar cada momento, alguns ser-cuidadores conseguiram refletir e projetar o seu porvir, remontar o vigor de ter sido e modificar o seu presente.

Pois, a temporalidade traz ao ser-aí a capacidade de anteceder a si mesmo compreendendo sua facticidade existencial. Dessa forma, é exequível ao cuidador ressignificar a sua história afastando a concretude de uma vida fixada na frustração e em sentimentos negativos ${ }^{(6)}$. Isso o faz sentir sua vida restaurada e, principalmente, o seu poder ser próprio, ou seja, ser um ser-do-cuidado.

Os cuidados paliativos, como uma assistência diferenciada, pode contribuir para o repensar da atuação destes ser-cuidadores. Ao atuar em consonância com as proposições paliativistas, torna possível ao enfermeiro estar em relação com o outro em um determinado tempo e espaço existencial. E, nesta maneira de ser-uns-com-osoutros-no-mundo o cuidado se manifesta como uma possibilidade de preocupação do ser consigo mesmo, incentivando-o a preocupar-se também com os outros ${ }^{(24)}$. Desta forma, os ser-cuidadores talvez compreendam o quão imperioso é não renegar a doença de seu familiar, refletindo que muitas coisas ainda podem ser realizadas e que o "existir" supera a cura.
Na condição de elevada dependência o cuidado ao familiar adoecido se torna imperativo haja vista erradicar o câncer seja uma possibilidade longínqua, assim, desvelar os desejos e anseios aquém do dito do doente e sua família podem ajudá-los a compreender a temporalidade da condição, e então libertá-los das amarras do mundo cotidiano. Ao ter consciência do próprio poder-ser e de sua liberdade, o ser produz iniciativa, espontaneidade e criatividade $^{(20)}$, o que permite encontrar caminhos para atender suas vontades mais ocultas.

Nos cuidados paliativos, a comunicação é um instrumento valioso na implementação de ações de cuidado. Se adequada é compreensiva para com o paciente e família, valorizando as experiências como um processo que influencia os significados atribuídos à doença e a terminalidade e, por conseguinte, as suas decisões, as quais devem ser ponderadas nas estratégias de tratamento ${ }^{(12)}$.

Os profissionais de enfermagem da ESF ao acompanhar as famílias podem estabelecer através da comunicação uma relação de vínculo e confiança. Isso contribui ativamente neste processo de cuidado do cuidador e seu dependente, consolidando uma assistência paliativa efetiva. A assistência de enfermagem ao cuidador deve privilegiar informações, esclarecer dúvidas e ajudá-lo no enfrentamento das dificuldades com os recursos apropriados às suas necessidades socioculturais $^{(6)}$.

Ao saber escutar e promover o crescimento do outro se torna factível incorporar a ciência dos cuidados paliativos à arte de cuidar, propiciando melhorias no atendimento prestado. Assim, somente através dessa comunicação efetiva é possível compreender a temporalidade vivenciada por esses seres e, então apoiar o doente de câncer e sua família com vistas a uma assistência integral, resolutiva e coerente com suas subjetividades.

\section{CONCLUSÃO}


Significou para o ser-cuidador ao assumir a responsabilidade de assistir um familiar com câncer e dependente ter a sua rotina e vida modificadas pela doença do outro. Com isso, rememorou o vigor de ter sido de seu familiar, bem como o seu. Ora se manteve preso a esta ek-stase, fechando-se para as diferentes possibilidades; ora vislumbrou um porvir promissor e modificou o seu instante.

Inserir-se no território e acompanhar as famílias de sua responsabilidade possibilita aos trabalhadores de saúde, em especial aos profissionais de enfermagem, compartilhar o mundo desses seres, instigando-os a repensarem suas ações cotidianas aprisionadas no vigor de terem sido que ocultam seu poder ser mais próprio. Deve-se enaltecer o porvir dentre as ek-stases, para que esse prevaleça no pensamento e ações do ser-cuidadores, pois, deixar vir a si as possibilidades de ser pode tornar o instante realista e menos sofrido.

Assim, olhar para a temporalidade faz-se necessário para que os profissionais compreendam as diferentes

\section{REFERÊNCIAS}

1. Sanchez KOL, Ferreira NMLA. O apoio social para a família do doente com câncer em situação de pobreza. Texto contexto enferm. 2012;21(4):792-9.

2. Williams AL, Bakitas M. Cancer family caregivers: a new direction for interventions. J. palliat. med. 2012;15(7):775-83.

3. Mosher CE, Champion VL, Azzoli CG, Hanna N, Jalal SI, Fakiris $\mathrm{AJ}$, et al. Economic and social changes among distressed family caregivers of lung cancer patients. Support. care cancer. 2013; 21(3):819-26.

4. Lamino DA, Turrini RNT, Kolcaba K. Cancer patients caregivers comfort. Rev. Esc. Enferm. USP 2014; 48 (2): 274-80. 5. Mc Lean LM, Walton T, Rodin G, Esplen MJ, Jones JM. A couple-based intervention for patients and caregivers facing end-stage cancer: outcomes of a randomized controlled trial. Psycho-oncol. 2013; 22 (1): 28-38.

6. Anjos ACY, Zago MMF. Ressignificação da vida do cuidador do paciente idoso com cancer. Rev. Bras. Enferm. 2014; 67(5): 752-8.

7. Araújo LZS, Araújo CZS, Souto AKBA, Oliveira MS. Cuidador principal de paciente oncológico fora de possibilidade de cura, repercussões deste encargo. Rev. bras. enferm. 2009; 62(1):327.

8. Sales CA. Cuidado paliativo e o profissional enfermeiro. Cienc. Cuid. Saude. 2010; 9 (3): 417-22. nuances dessa vivência, bem como considerem os desejos do binômio doente-cuidador, colocando-os em uma posição de agentes terapêuticos e não meros pacientes.

É justamente esse cuidar autêntico, pautado nos cuidados paliativos, que deve ser constatado quando presente no cotidiano do ser-cuidador, apresentado e incentivado quando ausente e fortalecido quando em descrédito. Além disso, deve ser desenvolvido, a exemplo, pelo profissional enfermeiro com o intuito que se alcance o objetivo maior dos cuidados paliativos e da enfermagem, ou seja, assumir o seu projeto essencial de ser um ser-do-cuidado.

Destaca-se que não é possível generalizar os resultados deste estudo a outras equipes da ESF de outros municípios, haja vista que seus achados detêm-se ao tempo e espaço das vivências dos depoentes pela própria natureza qualitativa da pesquisa. Mesmo com tais limitações, acredita-se que este possibilitou reflexões importantes, contribuindo para expansão do conhecimento acerca da temática.

9. Boemer MR. Sobre cuidados paliativos. Rev. esc. enferm. USP. 2009;43(3):Editorial.

10. Simino GPR, Santos CB, Mishima SM. Acompanhamento de usuários, portadores de câncer, por trabalhadores da saúde da família. Rev. Latino-am. Enfermagem. 2010;18(5):856-63.

11. Sales CA, D'Artibale EF. O cuidar na terminalidade da vida: escutando os familiares. Cienc. cuid. saude. 2011;10(4):666-73. 12.Cruzeiro NF, Pinto MH, Cesarino CB, Pereira APS.

Compreendendo a experiência do cuidador de um familiar com câncer fora de possibilidade de cura. Rev. Eletr. Enf. [Internet]. 2012. [acesso em 21 abr 2015];14 (4): 913-21. Disponível em: http://www.fen.ufg.br/revista/v14/n4/v14n4a20.htm.

13. Heidegger M. Ser e tempo.6a ed. MSC Schuback, tradutora. Petrópolis: Vozes; 2012.

14. Maciel MGS, Carvalho RT. Palliative performance scale PPS: versão 2. Tradução brasileira para a língua portuguesa [Internet]. São Paulo; 2009. [acesso em: 24 jun 2013]. Disponível em:

http://www.victoriahospice.org/sites/default/files/pps_portug ese.pdf.

15. Mutti CF, Padoin SMM, Paula CC, Souza IEO, Terra MG, Quintana AM. Cuidado de enfermagem à criança que tem doença oncológica avançada: ser-com no cotidiano assistencial. Cienc Cuid Saude. 2012; 11(1):113-20. 
16. Paula CC, Souza IEO, Cabral IE, Padoin SMM. Movimento analítico hermenêutico heideggeriano: possibilidade metodológica para a pesquisa em Enfermagem. Acta paul. enferm. 2012; 25 (6): 984-9.

17. Josgrilberg RS. A fenomenologia como novo paradigma de uma ciência do existir. In: Pokladek DD, organizador. A fenomenologia do cuidar: prática dos horizontes vividos na área da saúde, educacional e organizacional. São Paulo: Vetor, 2004. p. 75-93.

18. Oliveira MFV, Carraro TE. Cuidado em Heidegger: uma possibilidade ontológica para enfermagem. Rev. bras. enferm. 2011; 64(2): 376-80.

19. Fernandes MA. O Cuidado como Amor em Heidegger. Rev. abordagem Gestál. 2011; XVII(2): 158-71.

20. Seibt CL. Temporalidade e propriedade em Ser e Tempo de Heidegger. Rev. Filos. 2010; 22(30): 247-66.

21. Kirchnner R. A fundamental diferença entre o conceito de tempo na ciência histórica e na física: interpretação de um texto heideggeriano. Veritas [Internet]. 2012 [acesso em 19 dez 2012]; 57(1):128-42. Disponível em:

http://revistaseletronicas.pucrs.br/ojs/index.php/veritas/articl e/view/11230/7674.

22. Baptista BO, Beuter M, Girardon-Perlini NMO, Brondani CM, Budó MLD, Santos NO. A sobrecarga do familiar cuidador no âmbito domiciliar: Uma revisão integrativa da literatura. Rev. Gauch Enferm. 2012; 33(1):147-56.

23. Sales CA, Matos PCB, Mendonça DPR, Marcon SS. Cuidar de um familiar com câncer: o impacto no cotidiano de vida do cuidador. Rev. Eletr Enf. [Internet]. 2010 [acesso em 01 mar 2013]; 12 (4): 616-21. Disponível em:

http://www.fen.ufg.br/revista/v12/n4/v12n4a04.htm. 24. Sales CA, Violin MR, Santos EM, Salci MA, D'Artibale EF, Decesaro MN. Cuidados paliativos: relato de experiência de sua aplicabilidade em um projeto de extensão. Cienc. cuid. Saude. 2009;8 suppl:125-9.

Recebido: 01/04/2014.

Aceito: $16 / 04 / 2015$.

Publicado: 30/09/2015. 